\title{
Conducting ethnography in medical settings
}

\author{
Catherine Pope
}

BACKGROUND Ethnographic research methods have a considerable history of use in medical settings. This paper provides a personal account of conducting ethnography in medical environments and focuses on some of the practical and ethical issues encountered in such settings.

\section{DISCUSSION AND CONCLUSION The paper} describes particular issues that arise when undertaking ethnographic work, such as gaining access, recording data, research roles and researching elite groups, and recounts some of the dilemmas posed by doing this type of research in a medical setting. The paper concludes by reflecting on what ethnography might offer to medicine in return for the rich data medicine provides.

KEYWORDS humans; *anthropology, cultural; *biomedical research; research design; *education, medical; ethics, medical; ethics committees, research; data collection; professional practice; Great Britain.

Medical Education 2005; 39: 1180-1187

doi:10.1111/j.1365-2929.2005.02330.x

\section{INTRODUCTION}

As Pugsley and Atkinson ${ }^{1}$ point out, ethnographic research methods have been used to study medical education for nearly 50 years, and to examine the world of medicine for even longer. The term 'ethnography' encompasses a number of methods of collecting data, as well as different analytical strategies, but the practice of ethnography typically involves lengthy participation or immersion in the everyday life of a chosen setting. This is accomplished

School of Nursing \& Midwifery, University of Southampton, Southampton, UK

Correspondence: Catherine Pope, School of Nursing \& Midwifery, University of Southampton, Highfield SO17 1BJ, UK.

Tel: 00442380 598293; Fax: 00442380 598308; E-mail:

cjp@soton.ac.uk by becoming part of that everyday life, principally by observing interactions and behaviour, but also by talking to the members of the social world being studied and looking at the documents or artefacts they produce.

This paper provides a personal account of what it is like carrying out this kind of research in medical settings. I focus on some of the practical and ethical issues I have encountered and address 4 questions:

- How do ethnographers gain access to the setting?

- How are data recorded?

- Is there a fixed role for the researcher?

- Are there special issues involved in researching elite groups?

What follows is grounded in my personal experience. Like other qualitative research, ethnography relies on the researcher to act as the research instrument, and, undoubtedly, who I am and the settings I have worked in have shaped my experience (see Contributor and Appendix 1). The paper ends with some reflections on what ethnographic research has to offer to medicine and medical education.

\section{GETTING IN: ACCESS TO MEDICAL SETTINGS}

People are sometimes surprised at the idea that it is possible to conduct ethnography in medical settings, especially the non-public spaces or 'backrooms" of medicine, such as operating theatres. In the 3 cases drawn on here, I did not encounter difficulties obtaining access, primarily because of the access route chosen. In each case my presence as a researcher was legitimated by sponsorship or by an introduction by someone inside the organisation concerned (see below). Fox ${ }^{3}$ who used a similar route in his study of surgical teams, and Ostrander, ${ }^{4}$ recounting her studies of elite groups, confirm that 


\section{Overview}

\section{What is already known on this subject}

Ethnography involves lengthy participation or immersion in a setting.

\section{What this study adds}

The degree of participation in the life of the setting varies. Research roles are not fixed; they move along a continuum from observer to participant. Consent may need to be renegotiated as the research becomes embedded, and it is important to consider the impact of routes into the setting.

Typically, the ethnographer occupies a more powerful position than his or her subjects do. Ethnography in medical settings often reverses this hierarchy, so it is important to consider the impact of social differences.

\section{Suggestions for further research}

Ethnography can provide insights for medical practice and education. Further research could explore how these methods can be used in clinical training.

access is not always problematic. Nonetheless, the novice researcher or those unable or unwilling to go through gatekeepers may find gaining access difficult.

Before entering the field there is a substantial hurdle to be surmounted, namely, gaining ethical approval (see the recent web survey reported in the British Medical Journa $\tilde{P})$. In the UK, this is overseen by a system of research ethics committees (RECs). Over the years, in response, in part, to pressure from researchers, there have been various attempts to refine the process, but it remains a lengthy and complex bureaucratic process. The surgical outcomes project on which my study of surgical practice was based took place before the advent of multicentre RECs and required 32 separate applications for approval, each using unique, lengthy forms and slightly different processes. The REC system, designed primarily as a mechanism for governing quantitative experimental research, often fails to understand the nature of ethnographic research ${ }^{6}$ (e.g. it is often not possible or appropriate to fix a 'sample size' at the outset) and REC members may not have the requisite expertise to judge a qualitative protocol. In more recent months these difficulties have been compounded by research governance requirements, which, for example, mean that all research has to be approved and registered by the particular health care organisation involved. It is increasingly difficult for researchers outside the NHS to identify the particular individuals within these organisations who can grant such permissions, and, again, the process often involves protracted negotiations, form-filling and, in many cases, the requirement to hold 'honorary contracts' with the relevant organisations. In the majority of cases, the risks posed by an ethnographic study when compared, say, with interventions in many randomised controlled trials, are minimal. Nonetheless, ethnographers working in medical settings must assess and address potential risks. Thus, for example, in order to conduct research in operating rooms in the USA, I was briefed on their occupational safety and health administration guidelines and informed about what to do, for example, in the event of contact with blood or bodily fluids.

So how did I gain access for the 3 studies described here? When I conducted my research into surgical practice I was already involved in research about surgical outcomes. Through this I built up a network of contacts in the UK, who not only provided me with access to their organisations but were also able to suggest possible contacts in the USA. The latter I approached by letter, outlining the purpose of my study and explaining that I would like to observe and talk to them. Looking back over this letter, I realise I did not mention ethnography; I simply stated that I was a social scientist interested in finding out about surgical practice and techniques. Possibly I was unusually lucky, but only one of the UK surgeons declined to be interviewed (because he could not spare the time) but he did allow me to watch him operating, and none of the American surgeons refused to take part. In the study of anaesthetists, access was facilitated by the consultant anaesthetist who was part of the research team and, perhaps unsurprisingly, we encountered few difficulties entering this field. In the study of waiting list management, I was able to hang around in the admissions office with the permission of senior managers who had instigated the research project of which my ethnography was a part. The office staff were a little bemused by my interest but did not object to my presence. Indeed, all the health professionals and other workers who have been part of the research I have undertaken to date have 
seemed comfortable letting me into their worlds. I suspect that this partly reflects the novelty of having an outsider profess fascination with the minutiae of your everyday work.

From these 3 examples, access to hospital settings appears relatively straightforward, but it is worth considering the impact of routes into the organisation or group. The point of entry and alliances with powerful gatekeepers in the organisation influence how group members perceive the research. The onus is on the researcher to reflect on these relationships and the power imbalances they engender. One virtue of the composition of the team for the study of anaesthetists was that we were able to draw on the presence of another insider in the research team (an ex-nurse), who was able to build on her prior relationships with anaesthesia teams to verify that our presence was accepted by non-medical and more junior staff. For my work with surgeons, where I was the sole researcher, I was frequently introduced to other members of the surgical team, and to patients, by senior surgeons who assumed that there were no objections to my presence. With hindsight, this was inadequate, but at the time, as a relative novice, I did not question the legitimacy of gaining access in this way.

Whatever the route into the setting, it is important to be aware that negotiating access and consent is a process. Ethical issues are often magnified in medical environments, not least the issue of 'informed consent'. I think we handled this best in the anaesthetic expertise study, where we used meetings to describe the study to all the staff involved and explained that they could decline to take part or ask us to leave at any point during the fieldwork. In addition, although the study was not about patients, the researcher met each patient prior to his or her surgery and obtained written permission to observe the operation. We were also careful to renegotiate access and consent with staff each time we observed them. Yet even in this study we were often forced to remember that ethnography and, by extension, consent are not single events but involve a negotiated process. Consent may be readily given at the outset, but as the research becomes embedded participants forget you are there. My colleague Dawn Goodwin ${ }^{7}$ has documented how, for example, anaesthetists discussed confidential matters in her presence. The fact that the researcher was party to these conversations suggested little evidence of a Hawthorne effect (changes to participants' behaviour due to the research being carried out) but the situation posed a problem for consent. One very practical way I have tried to deal with this is by, where possible, openly writing notes during observation as a way of signalling that research was happening. Even so, participants may need to be reminded that research is ongoing and sometimes, as Emerson et al. ${ }^{8}$ note, such openness can put a strain on relationships with participants or distract the researcher's attention.

\section{RECORDING DATA}

The subject of writing notes leads us into the question of how data are recorded. Ethnography is rooted in writing. Lengthy periods of observation require hours of copious note taking and writing. 'Notes in the field' or 'jottings' are the starting point for data collection. It is not always appropriate to take notes contemporaneously - conversations over lunch, or when walking to a meeting, may have to be remembered and written down later. Sometimes it is necessary to focus on watching the action without writing. Like others before me, I found that toilet breaks provided an excellent opportunity to quickly write notes, especially if privacy was required. My jottings, which run to many notebooks, are embarrassingly scruffy, consisting of fairly untidy writing, hasty sketches, and idiosyncratic abbreviations and shorthand (Fig. 1). I aim to write up these notes even if only in neat long-hand - on the same day and to type them as soon as possible as field notes.

Ethnographic data collection rarely fits neatly into a 9-5 working day: I recall that much of my 'free' time during my US fieldwork was spent writing field notes in my motel room. Field notes (see Appendix 2) provide the raw material for the analysis. My own notes can be characterised using the typology provided by van Maanen ${ }^{9}$ as realist; I try to document the minutiae of life in the setting and offer a single reading or version of events. This is very much a personal style, developed over time, and, whilst I admire other sorts of ethnographic writing, I find that these kinds of field notes are the ones I produce most comfortably. Working in a team on the anaesthetists project, I found that this style of field note also had the virtue of being transferable within the team, that others were able to follow the story. (Emerson et al. ${ }^{8}$ give a longer, helpful exposition of different types of ethnographic field notes.)

Recording technology has its uses and, where possible, I audio-record formal interviews but use an oldfashioned pen or pencil and notebook for most of my data recording. On the anaesthetic expertise project we had lengthy discussions about whether to video operations but we were not convinced there were 


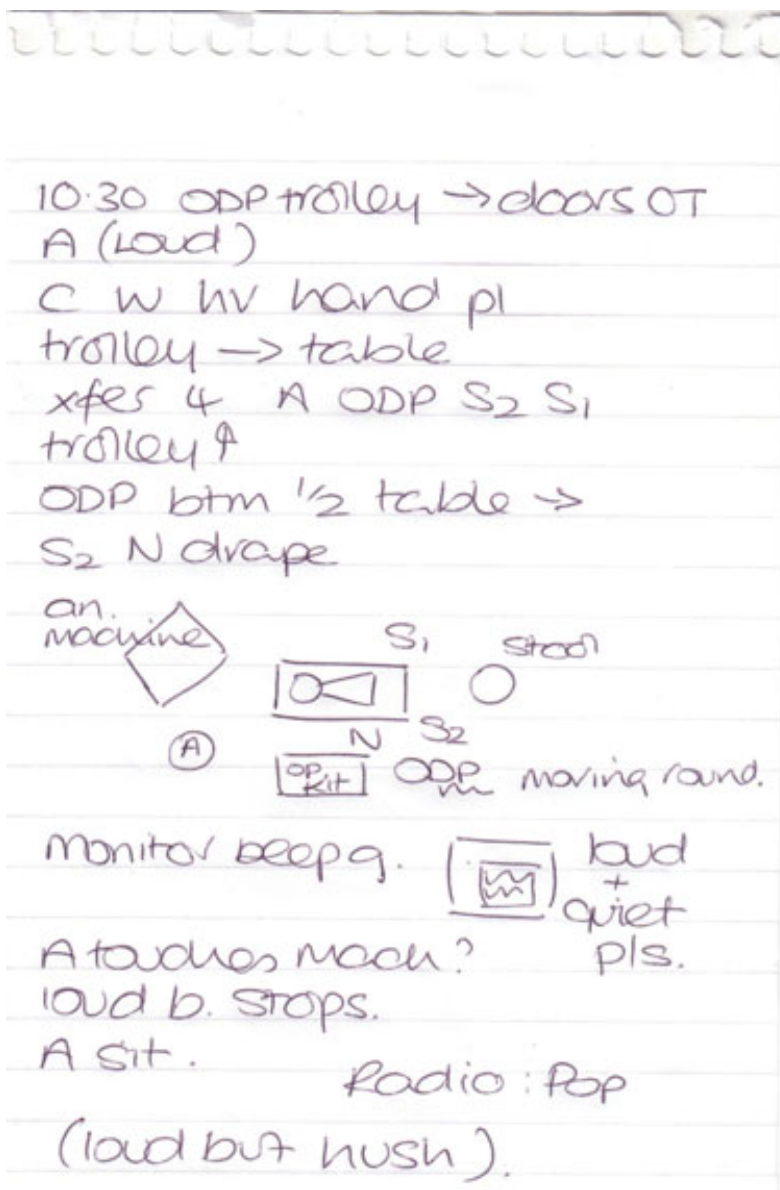

Figure 1 Example of a typical field note, including diagram, from the study on anaesthetics expertise.

strong methodological reasons for this (as we were not analysing the minutiae of professional talk as in conversational analysis - see Heath ${ }^{10}$ for an example) and felt that the flexibility provided by a roving researcher offered more benefits to this particular study. Whatever the recording methods, eventually the raw data must be transformed by transcription and further writing to provide the rich reconstructions that are the basis of the analysis. Be warned: this process takes many hours.

\section{RESEARCH ROLES}

The term 'participant observation' is often used as a synonym for ethnography, describing the researcher who actively takes part in the life of the group being studied. The degree to which a researcher can actually participate in the life of the setting varies. Gold's classic typology of research roles ${ }^{11}$ characterises participation on a continuum from 'complete participant' to 'complete observer' (Fig. 2). As a non-medic, I have never been a complete participant, although working on the anaesthetists project we were able to draw on 'emic' or insider perspectives of the 2 health professionals on the team. I have found, however, that research roles are not fixed or static when doing ethnography. In each setting I have entered, I have initially been an outsider and a complete observer. An early field note from the study of surgeons provides an example of this. I had just been introduced to 2 trainee surgeons, Kay and Ed. Ed had asked me about the study:

I chat to Kay and Ed. Ed is still unsure of why I am there and what I am up to. We talk about the study some more and I ask him about the differences between the way different surgeons operate. For me this is a central theme of my research. For Ed, this is something he knows - he has worked with several different surgeons, including some involved in the current study. This conversation provokes a spirited discussion between Ed and Kay about who can do a particular procedure the fastest. They include me in this conversation by explaining terms that I might be unfamiliar with and joking about their competitive display. (Surgery study field note, 1994)

As my relationship with these surgeons developed over the course of the study, I felt that I became more integrated into the group and moved closer to the participant role. At the beginning of my research I remember feeling that I had entered an alien world. My notes reflected this: early on I wrote about my responses to the situation - I felt nauseous and I was aware of the different smells of blood and chemicals. I recall being unsure about the best vantage point from which to view surgery (I am not very tall and I often ended up being given a stand or step, so that I too could peer into the abdominal cavity). I found that I identified with the patient, and was struck by the contrast between the violence of procedures for pulling back the skin and tissues to reveal internal organs and the intricacy of some of the surgical suturing. Later in the research, I focused more on surgical techniques: I began to 'see' practice variations, and became adept at anticipating

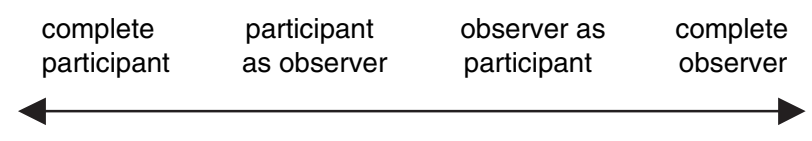

Figure 2 Gold's typology of research roles. 
procedures. I also became more accepted, as this excerpt indicates:

Hugh does some more suturing and takes some sterile cloth out of a container. It is quite a long strip. This will be used to elevate the bladder. I notice that these days in the operating theatre I don't get nauseous anymore, even with these big abdominal procedures, but I feel quite cold, it is not the warmest theatre I've been in. Hannah gets me a scrub gown to wear as I am near the operating table. Dan, who is assisting, asks me if I operate lefthanded and I laugh and explain that I don't operate at all! (Surgery study field note, 1994)

\section{RESEARCHING ELITE GROUPS}

In much research, the researcher occupies a more powerful position than the research subjects. Ethnography in medical settings often reverses this hierarchy and power balance. The ethnographer may be the more junior party, if not in age, at least in terms of professional and occupational status, as our research frequently involves senior managers, clinicians and professional elites. Pierce ${ }^{12}$ describes this as 'studying up' and notes the additional effect on the research process of being a (subordinate) female researcher researching elite men. I was certainly aware of this in my own research, notably in the surgery project, which involved an area of surgery dominated by men. Sometimes I felt that my status worked in my favour - I was permitted to observe because I did not pose any threat - but on occasions I also felt that I was a 'mascot', just as Pierce describes. It is worth mentioning too that informants and interviewees from elite groups may be more likely to provide public accounts, effectively giving rehearsed presentations rather than the in-depth, unofficial story the researcher is looking for. The most extreme example of this I came across was in an interview with a surgeon, described in these notes:

When I initially made contact with $\mathrm{Mr} \mathrm{R}$ [he] said that he would prefer not to be tape-recorded. When we met, having gone through the outline of the study and consent he agreed to me taping our conversation. He also said that he did not have much time. He then proceeded to respond extremely slowly to each of my questions, giving fairly full answers but speaking almost as if he was dictating. This is the first time I have interviewed anyone who appears to be so affected by the recording process. It was rather unnerving. (Surgery study interview notes, 1993)

The presentation of public accounts provides further justification for employing a range of methods of data collection, including observing action as it occurs and engaging in informal interactions. During all 3 of the studies described here, I found that joining participants for meals, coffee and cigarette breaks, parties and other social events provided vital additional data for my analysis, as illustrated here:

$2.30 \mathrm{am}$. Deborah, the anaesthetist on-call, takes her meal break and I go with her to the small room just off the theatre corridor where breaks are taken. The scrub nurse, Sarah, joins us. They chat a bit about what Deborah is eating - it is from a machine in the canteen and looks unappetising. Then Sarah starts talking about a case that is going on in the obstetric operating theatre. Sarah says that she has told Anthony, the on-call surgical registrar, that he should not have started the final case. Sarah feels strongly that it is not fair on the obstetric patients to use the emergency team because we are all busy in this theatre. She feels that the operation (that I have just witnessed) could have easily waited until the morning... Sarah and Deborah go on to discuss several atrocity stories and behaviours of individual surgeons and these stories extend to a discussion about anaesthetists. They suggest that James has two basic anaesthetic techniques, whereas Nick has one technique and an 'occasional' technique. Both Sarah and Deborah admire another anaesthetist, Sam, who plans the technique and tells everyone in advance what is needed. They contrast this 'expertise' with Nick who is more 'chaotic'. Deborah says it is more difficult to work and train with someone like Nick. (Anaesthetists study field note, 2001)

\section{WHAT ETHNOGRAPHY CAN OFFER}

This paper has looked at how ethnography is accomplished in medical settings and some of the issues that confront researchers wishing to use these methods. The paper by Pugsley and Atkinson ${ }^{1}$ highlights the value of ethnography in informing medical education and making sense of life in medical school. Understanding the ethnographic approach may also provide other insights. Elsewhere, with colleagues from the anaesthetists expertise study, I have suggested that the systematic observational methods employed in ethnographic research 
might be used in clinical training to examine and refine practice. ${ }^{13}$ Reflexivity - thinking critically about roles and relationships, about ethics and responsibilities - is a central part of ethnography. Moreover, carrying out ethnographic research with people in medical settings can provide a catalyst for reflection and opportunities to feedback to doctors and other health care professionals. One of the participants in the anaesthetists study described the process of being involved in ethnographic research as enriching, but perhaps the best description of the insights offered by such research comes from another 'Doc' - a participant in one of the classic ethnographic studies (of street gangs) - who said: 'You've slowed me up plenty, now when I do something I have to think, "What would Bill Whyte want to know about it?" Before I used to do things by instinct."14

To sum up, performing ethnographic research is neither quick nor easy, and there are particular issues to be addressed in conducting ethnography in medical settings. Nonetheless, it has a lot to offer, both to social and medical research and to practitioners and health care professionals.

Contributor: I am a medical sociologist and health services researcher. The first ethnographic project described in this paper was conducted when I was in my early 20 s. I began my research career working for a hospital department and have since worked in university public health, policy and health services research. When I started out I had no prior knowledge of medicine or the health services, nor had I any substantial contact with the health care professions (I have no serious longstanding illness or disability, and no close relatives 'in the trade'). In the later part of my career I have spent some 10-12 years teaching postgraduate and undergraduate medical students and thus have increased my contact with the world of medicine and health care. I have also worked with a number of collaborators from a variety of health care professional backgrounds. I am female and have what can be politely described as a working class (South) London accent. All of the above may have affected my experiences in ethnography.

Acknowledgements: I thank all the participants in the research described in this paper. I also thank my colleagues Andrew Smith, Maggie Mort, Dawn Goodwin, Nick Black, Ann Bowling, Paul Abel, Jenny Stanley and Jenny Roberts for their respective roles on the anaesthetic expertise, surgical outcomes and waiting list projects. As ever, I acknowledge my great debt to the late Phil Strong for inspiring and encouraging me to undertake ethnography. Funding: the anaesthetic expertise study was funded by a grant from NHS North-west Research and Development (RDO 28/03/05). The US fieldwork for the surgical practice study was funded by a Wellcome Trust travel grant and additional funds supplied by Lectromed UK Ltd. The main surgical outcomes study, on which some of the surgical practice work was based, was funded by the Medical Research Council (SPG9117416). The waiting list study was funded by the Locally Organised Research Scheme for North-east Thames Region (1988).

Conflicts of interest: none.

Ethical approval: ethical approval for the anaesthetic expertise project was granted by Southmead LREC (123/01) and Lancaster LREC (CW/L523) and for the surgical outcomes study by 32 LRECs in North Thames Regional Health Authority Area.

\section{REFERENCES}

1 Atkinson P, Pugsley L. Making sense of ethnography and medical education. Med Educ 2005;39:228-34.

2 Goffman E. The Presentation of Self in Everyday Life. Harmondsworth, UK: Penguin 1990. [First published 1959.]

3 Fox N. The Social Meaning of Surgery. Milton Keynes: Open University Press 1992.

4 Ostrander SA. Surely you're not in this just to be helpful: Access, Rapport, and Interviews in three studies of Elites. In: Hertz R, Imber J, eds. Studying Elites using Qualitative Methods. London: Sage 1995;94-110.

5 http://bmj.bmjjournals.com/cgi/eletters/330/7487/ 361. [Accessed 19 July 2005.]

6 Langer S. Protecting patients - managing persons. http:/ /www.anthropology.matters.com 2005: 7(1). [Accessed 19 July 2005].

7 Goodwin D, Pope C, Mort M, Smith A. Ethics and ethnography - an experiential account. Qualitative Health Res 2003;13:567-77.

8 Emerson R, Fretz R, Shaw L. Writing Ethnographic Fieldnotes. Chicago: University of Chicago Press $1995 ; 23$.

9 van Maanen J. Tales of the Field: on Writing Ethnography. Chicago: University of Chicago Press 1988.

10 Heath C. The analysis of activities in face to fact interaction using video. In: Silverman D, ed. Qualitative Research Theory, Methods and Practice. London: Sage 1997.

11 Gold R. Roles in sociological field observation. Social Forces 1958;36:217-23.

12 Pierce J. Reflections on fieldwork in a complex organisation. In: Hertz R, Imber J, eds. Studying Elites using Qualitative Methods. London: Sage 1995;95-110.

13 Pope C, Smith A, Goodwin D, Mort M. Passing on tacit knowledge in anaesthesia: a qualitative study. Med Educ 2003;37:650-5.

14 Whyte WF Street Corner Society. Chicago: University of Chicago Press 1955;301.

15 Pope C. Trouble in store: some thoughts on the management of waiting lists. Sociol Health Illness 1991;13(2):193-212.

16 Pope C. Contingency in surgical work and some implications for evidence-based surgery. Sociol Health Illness 2002;24(4):369-84. 
17 Pope C. Resisting evidence: contemporary social movements in medicine. Health 2003;7:267-82.

18 Smith AF, Goodwin D, Mort M, Pope C. Expertise in practice: an ethnographic study exploring acquisition and use of knowledge in anaesthesia. BrJ Anaesth 2003;91:319-28.

19 Smith A, Pope C, Goodwin D, Mort M. Communication between anaesthesiologists, patients and the anaesthesia team: a descriptive study of induction and emergence. Can J Anaesth 2005;52:915-20.

Received 27 April 2005; editorial comments to author 24 June 2005; accepted for publication 6 September 2005

\section{APPENDIX 1}

\section{The studies}

\section{Waiting lists for elective surgery}

Fieldwork, conducted between 1989 and 1990 in a non-teaching district hospital in England, was part of a larger project using quantitative analysis of routine statistics collected by the hospital and including a postal survey of patients. The focus of the ethnography was the people-processing activities of what are called the 'lower order participants' in organisations in this case the medical clerks and secretaries who managed elective care waiting lists. The research question was: 'How do waiting lists really work?' Hospital managers saw the lists as queues, operated on a first-come, first-served basis. The ethnographic work showed that staff who managed and used the lists on a daily basis viewed them not as queues, but as repositories or 'stores' servicing the varied, sometimes competing, needs of different groups and individuals within the organisation. ${ }^{15}$

\section{Surgical practice}

Fieldwork was conducted between 1991 and 1994 in England and the USA. Observation of operations, ward rounds and teaching sessions, and interviews with surgeons and informal conversations and opportunities to observe interactions with other staff, clinics, meetings and conferences, etc. centred on a core group of 34 surgeons. Research questions sought to understand how surgeons accomplish surgery and how they acquire new skills and knowledge. From this I developed ideas about contingency - that surgical practice is at once conditional and subject to chance ${ }^{16}$ and explored the dualism of tacit/explicit knowledge to develop a critique of evidence-based surgery. ${ }^{17}$

\section{Anaesthetics expertise}

Conducted by a team of 4 researchers from social science and clinical backgrounds, this fieldwork was carried out between 2000 and 2002 in 2 English hospitals. The main site involved 25 anaesthetists and the second, comparative site, where we spent less time, involved 39 anaesthetists. We collected some 130 hours of direct observation of anaesthetists at work in different hospital settings (theatres, wards, etc.), and conducted interviews and collected documentary material pertaining to anaesthesia practice. From these data we were able to examine routes to the acquisition of expertise, notably, the importance of the apprenticeship model of training and the role of tacit knowledge, ${ }^{13}$ the use of personal routines ${ }^{18}$ and communication. ${ }^{19}$

\section{APPENDIX 2}

\section{Excerpt from field notes}

Anaesthetic expertise study, observation session with DG, 2000

$10.30 \mathrm{am}$. The ODP (operating department practitioner, male) wheels the patient on the trolley through the double doors to the operating theatre. The anaesthetist says, loudly, in the direction of the operating theatre, 'Can we have a hand please.' They wheel the trolley next to the operating table and 4 people including the ODP and anaesthetist slide the patient onto the operating table. The trolley is moved out of the way. The patient is positioned, and the lower part of the table is removed by the ODP. Drapes are placed over the body by the surgeon and the scrub nurse.

The monitor is beeping - loud intermittent beeps and behind this a quieter pulse sound. The anaesthetist looks at the monitor and, I think, touches something. [Note: DG's field notes show that the gases were adjusted at this point.] The louder beep stops. Other people are busy with other pieces of operating equipment. The anaesthetist sits down on a stool near the monitor [Fig. 1]. The radio is on, playing loud pop music - another noise in this room that people don't really seem to take notice of. My impression is that it is quiet in here - if you listen there are sounds but the noise is in the background and not attended to. The conversations are not loud. 
This contrasts with the earlier anaesthetic room where patients are talked at/to and instructions are more audible. It is kind of reverential.

The 2 surgeons talk to each other and to us [CP and DG, the 2 ethnographers]. They want to know if we are watching them. We engage in some light-hearted banter about this - that they (surgeons) are not as interesting to us as anaesthetists! We laugh together.

The anaesthetist adjusts a dial on the front of the anaesthetic machine and looks at the monitor and at the surgeons. He sort of half rises to his feet but doesn't stand up completely to do this. He writes on the anaesthetic chart that had been on the desk area under the monitor. He writes on the blue and white pages, which I know is the prescription record. He checks the monitor while flicking through the notes. He discusses the notes with the nurse and takes out a page and hands it to the nurse [I don't see what she does with this but conferring with DG I find that this was identity stickers to go onto forms that the nurse was completing at a desk at the side of the room]. Then he writes on the anaesthetic chart - the red and white pages. He occasionally looks directly at the patient at her face and at the surgeons.

A pulse sound is audible. The lights on the anaesthetic monitor include 'trace lines' [like those that you see measuring heart rate] green on top, then white and then purple and another green, one above the other. The black balloon on the lower part of the anaesthetic machine slowly inflates and deflates, breathing for/with the patient. This seems oddly calming/reassuring.

The second surgeon wanders out of the operating theatre. The anaesthetist stands up still holding the notes and moves to the doors leading back to the anaesthetic room. He opens one of the doors and stands asking a question - I can't hear this, nor see whom he is addressing. He then moves back to the patient and puts the notes on the desk and stands by the monitors, adjusting [gases], looking at the screen and then the patient. He 'tidies up' some tubes that were lying on the desk and disposes of them in the yellow bag marked clinical waste.

The male orderly comes in through a door at the side of the operating theatre. He helps to adjust the operating table and moves a trolley into position beside it. The surgeons' stool is moved out of the way. The anaesthetist begins disconnecting the monitoring. This is seamless, choreographed. While this is happening the monitor makes a louder slow-paced beeping noise and the top line of the traces is flat no-one looks alarmed or concerned but the anaesthetist is clearly busy, compared with the earlier watchful (in)activity. Five people transfer the patient to the trolley. A louder alarm sounds. The anaesthetist and ODP move to the recovery doors on the other side of the operating theatre and we go into recovery where the anaesthetist re-connects the patient to monitors. It is now $10.45 \mathrm{am}$. 